Ayodele John Alonge

University of Ibadan, Nigeria

Toluwase Victor Asubiaro

Western University, London, ON, Canada

University of Ibadan, Nigeria

\title{
Associations between Nollywood Movies and Risky Sexual Behaviours among in-School youths in Nigeria: An Ongoing Study
}

\begin{abstract}
Nollywood, the second largest movie industry in the world after America's Hollywood, is Nigeria's movie industry. This ongoing study investigates how sexual messages and scenes are communicated to viewers and if there is correlation between the pattern of Nollywood movies exposure and sexual behaviour of inschool adolescents in the southwestern part of Nigeria. Data will be collected from the participants through questionnaire while content of popular Nollywood movies among the participants will be content analyzed. It is expected that this study will provide information about the frequency of sexual scenes and how risky sexual behaviours are portrayed in Nollywood movies. Secondly, it is expected that this study will show the types of relationships that exist between movie exposure behaviour and sexual behaviour in the study population.
\end{abstract}

\section{Introduction}

Nigeria's population constitute about $25 \%$ of young people aged between 10 and 20 years of age (National Bureau of Statistics, 2018). With studies showing that average Nigerian youth debuts sex at the ages of 15 (Envuladu et al., 2017), their contribution of about $40 \%$ of new cases of HIV globally mainly because of unsafe sex(Adedokun et al., 2016), coupled with the proportion of this age group in the country's population, understanding the sexual behaviour of this population is important to the nation's health outlook. Besides, studies have shown that most young people at this age lack the requisite awareness about safe sexual habits (Envuladu et al., 2017), this has pitted the age of sexual debut as a strong factor that determines the risk of acquiring sexual transmitted diseases (Envuladu et al., 2017), unwanted pregnancy (Envuladu et al., 2017) and early childbearing/marriage which negatively affects the development of young women and increases their chances of dropping out of school (Odimegwu \& Somefun, 2017).

Risky sexual behaviour includes having multiple sex partners, engaging in sex with a risky or infected sex partner, early sexual debut, unprotected sexual intercourse with 'at risk' sexual partners, and untreated sexually transmitted diseases (Odimegwu \& Somefun, 2017; Oyediran et al., 2011). Risky sexual behaviour is influenced by alcohol and drug use, multiple sex partners, sex abuse (Okonkwo, 2013). Other risk factors are associated with gender, as men are more likely to take risk with unhealthy sexual behaviour than women (Erinosho et al., 2012). In addition, adolescents from poor background and uneducated parents are more at risk of participating in risky sexual behavior (Ugoji, 2014, Okonkwo, 2013). 
Studies have also found that there is a strong relationship between source of sexual information and sexual behaviour. For instance, studies have found association between the role of movies and social media as sources of sexual information of adolescents (O'Hara et al, 2012, Collins et al., 2011)). The influence of television and movie viewing among youths has been subject of research for some time. For instance, it was established that an hour of television viewing per day increases the tendency of a youth to start drinking alcohol by $9 \%$ (Robinson, Chen \& Killen, 1998; Gunasekera, Chapman, \& Campbell, 2005). Similarly, Sargent et al (2005) reported that $40 \%$ of youths who tried smoking did so based on what they see in movies, and that youths with highest exposure to movie smoking are 2.6 times likely to try the act than those with low exposure.

O'Hara et al (2012) confirmed that exposure to sexual scenes in movies affects the age of sexual debut. In fact, Kinsler et al (2018) reported that about $80 \%$ of adolescents learn about sex from television. As Nigerian youths spend ample time with television, cinemas, and the Internet to watch Nollywood movies, the information they internalise from the movies could influence their sexual behaviour. In fact, Nwagwu (2008) noted that television is the most effective source of information on HIV to adolescent girls in Nigeria. Nevertheless, preliminary review of literature showed research in Nigeria has not explored how contents from Nollywood movies is related to the risky sexual behaviours. However, there is a gap in the literature as the relationship between sexual behaviour and sources of sexual information has not been investigated in Nigeria. Therefore, this ongoing study is interested in investigating the relationship between Nollywood movies and sexual behaviour of adolescents in Nigeria.

The Nigerian movie industry, Nollywood, is the second largest movie industry in the world, ranked second, after Hollywood. It has been one of the major communication tools for cultural, historical, traditional and lifestyle messages among Nigerians and in Africa. The settings, plots and messages from Nollywood movies have significant impact on the lifestyle and behaviour of Nigerians (Ogwo, Asemah \& Ottah, 2015; Apuke \& Dogari, 2017), especially the youths (Nnabuko \& Anatsui, 2012; Udofia \& Tom, 2013; Omoera, Edemode \& Aihevba, 2017).

The specific objectives of the study are to investigate:

1. the extent to which Nollywood movies convey and praise unsafe sexual behaviour to viewers,

2. the movie exposure behaviour of the adolescents,

4. the perception of the adolescents concerning safe sexual behaviour,

5. the knowledge of the adolescents concerning safe sexual behaviour, and

6. the sexual behaviour of the adolescents

\section{Proposed Methodology}

This study will adopt mixed-method research design, that is, the use of both quantitative and qualitative study designs. Meeting the aims of the study requires the use of the qualitative research design through the content analysis of Yoruba and English Nollywood movie to explicate how sexual and HIV information is portrayed on the Nollywood movies; this will address the study objective one. The study will use quantitative research design to achieve objectives two, three, four and five. The first section discusses the survey with subsections on the population, sampling 
method, data collection and analysis. The second section discusses the content analysis with details on the sampling of movies, data collection method and content analysis method.

\section{$2.1 \quad$ Survey}

The survey comes first before the content analysis, this is necessary because the survey will include questions that will elicit information about movies that the study participants have watched. This information will be used to draw a list of top 200 most watched by the participants, for the content analysis.

\section{Population and Study Area}

The study population is the in-school senior secondary students in south western Nigeria. Students in this category in Nigeria are predominantly between the ages of twelve and sixteen and are mostly adolescents. The study area is the South Western Nigeria which consist of six states: Ekiti, Lagos, Ogun, Ondo, Osun and Oyo. Three states; One urban (Lagos State), one semi-urban (Oyo State) and one rural (Osun state) will be sampled purposively. Two secondary schools (one private and one public) will be purposively sampled from each of the three states, making six secondary schools. 75 students will be randomly sampled from each sampled secondary school, making a total of 450 students from the six secondary schools. The study area will be limited to the south western Nigeria alone considering time and logistics demand.

\section{Data Collection and Analysis}

Intended data collection instrument is questionnaire, which will be divided into five sections. The first section will elicit questions on the demographic characteristics of the students, which will include parents' level of education and income, household type, home access to internet, computer, television, religion and religious belief about movies' behaviour. Questions will also be asked about the names of movies participants have watched in the last one week, two weeks, one month and three months. The second section of the questionnaire will elicit questions on students' movies exposure behaviour which will include the average number of hours that students spend watching movies, if students watch movie alone, where the student watch move, if there are parental guidance on the content of movie students watch and the genre of movies students watch. The third section will elicit information on the students' perception about safe sexual behaviour and HIV. The fourth section will elicit information about the students' knowledge about sexual behaviours. The last section of the questionnaire will elicit information about the sexual behaviours of the students.

\subsection{Content Analysis of Nollywood Movies}

The content analysis of movies will follow the survey. Twenty most frequently watched movies will be created from the list of movies that students reported in the survey and will be content analysed.

\section{Data Analysis}

Each movie will be coded by two trained research assistants for the total length, in seconds, of portrayals of a variety of sexual-related, sexual risk behaviours and HIV discussions. Sexual related behaviours that will be coded include heavy kissing, intercourse, pre-intercourse romance 
and mooching. Sexual risk behaviours that will be coded include multiple sexual partners, sex for money, sex scenes without sighting condom (intended use) and sex under the influence of drugs or alcohol. Incidents per movie, length of time of these scenes and content of the scenes will be collected as data for further analysis. Content of the relevant scenes will be transcribed to textual formats manually in English language. Coding will take into consideration the level of exposure to sexual information; this could be strongly safe, somehow safe, neutral, somehow unsafe and strongly unsafe. The sentiments of the textual data will be content analysed to determine if unsafe sexual behaviours are glorified/encourage or discouraged in the movies using NVivo qualitative analysis software.

\section{Conclusion and Expected Outcomes}

It is expected that this study will give an insight to frequency of sexual related content and the portrayal of safe sex in Nollywood movies. Secondly, this study will provide information about the correlation between adolescents' sexual behaviour and Nollywood exposure behaviour.

\section{Acknowledgement}

This study was supported by the Consortium of Advanced Research and Training in Africa (CARTA), through the CARTA's doctoral re-entry grant for the year 2019, that was awarded to the first author as the principal investigator, and the second author as the co-investigator.

\section{References}

Adedokun, B., Olarinoye, O. M., \& Ilesanmi, O. S. (2016). HIV Prevalence and Predictors among Sexually Active Nigerian Youths. International Journal of Caring Sciences, 9(1), $114-124$.

Apuke, O.D \& Dogari, K.A. (2017). Western Television Programmes and Its Influence on the Cultural Values of Students' in Taraba State University, Jalingo, Nigeria. Canadian Social Science, 13(1): 21-32.

Collins, R., Martino, S., \& Shaw, R. (2011). Influence of New Media on Adolescent Sexual Health: Evidence and Opportunities (Task Order No. HHSP23337005T). The Administration for Children and Families (ACF) and the Office of the Assistant Secretary for Planning and Evaluation (ASPE) within the U.S. Department of Health and Human Services. https://aspe.hhs.gov/basic-report/influence-new-media-adolescent-sexualhealth-evidence-and-opportunities

Envuladu, E. A., Van de Kwaak, A., Zwanikken, P., \& Zoakah, A. I. (2017). Exploring the Factors Influencing Adolescent Sexual Behavior in Plateau State Nigeria. American Journal of Medicine and Medical Sciences, 7(1), 1-6. https://doi.org/DOI: 10.5923/j.ajmms.20170701.01

Erinosho, O., Isiugo-Abanihe, U., Joseph, R., \& Dike, N. (2012). Persistence of Risky Sexual Behaviours and HIV/AIDS: Evidence from Qualitative Data in Three Nigerian Communities. African Journal of Reproductive Health / La Revue Africaine de La SantéReproductive, 16(1), 113-123.

Gunasekera, H., Chapman, S. \& Campbell, S. (2005). Sex and drugs in popular movies: an Analysis of the top 200 Films. Journal of the Royal Society of Medicine, 98(10): 464-470.

Kinsler, J. J., Glik, D., De Castro Buffington, S., Malan, H., Nadjat-Haiem, C., Wainwright, N., \& Papp-Green, M. (2018). A content analysis of how sexual behaviour and reproductive 
health are being portrayed on primetime television shows being watched by teens and young adults. Health Communication, 1-8. Retrieved from https://www-tandfonlinecom.proxy.bib.uottawa.ca/doi/citedby/10.1080/10410236.2018.1431020?scroll=top\&ne edAccess $=$ true

National Bureau of Statistics, K. (2018). 2017 Demographic Statistics Bulletin (p. 26). https://nigerianstat.gov.ng/download/775

Nnabuko, J.O. \& Anatsui, T.C. (2012). Nollywood movies and Nigerian youths - an evaluation. JORIND, 10 (2): 214-222.

O’Hara, R.E., Gibbons, F.X., Gerrard, M., Li, Z. \& Sargent, J.D. (2012). Greater Exposure to Sexual Content in Popular Movies Predicts Earlier Sexual Debut and Increased Sexual Risk Taking. Psychological Science, 23(9): 984-993.

Odimegwu, C., \& Somefun, O. D. (2017). Ethnicity, gender and risky sexual behaviour among Nigerian youth: An alternative explanation. Reproductive Health, 14(1), 16. https://doi.org/10.1186/s12978-017-0284-7

Ogwo, C.A., Asemah, E.S. \& Ottah, G.A. (2015). Perception of the Portrayal of violence in Nigerian home videos: views from Anyigba, Kogi State. Review of Communication and Media Studies, 1(2): 30-39.

Okonkwo, A. D. (2013). Generational Perspectives of Unprotected Sex and Sustainable Behavior Change in Nigeria. SAGE Open, 3(1), 215824401247234. https://doi.org/10.1177/2158244012472346

Omoera, O.S., Edemode, J.O. \& Aihevba, P. (2017). Impact of Nollywood films on children's behaviour in Ekpoma, Nigeria. Asian and African Studies, 26(2): 350-374.

Oyediran, K. A., Feyisetan, O. I., \& Akpan, T. (2011). Predictors of Condom-use among Young Never-married Males in Nigeria. Journal of Health, Population and Nutrition, 29(3), 273-285. https://doi.org/10.3329/jhpn.v29i3.7875

Robinson, T.N., Chen, H.L. \& Killen, J.D. (1998). Television and Music video exposure and risk of adolescent alcohol use. Pediatrics, 102(5): e54.

Sargent, J.D., Beach, M.L., Adachi-Mejia, A.M., Gibson, J.J., Titus-Ernstoff, L.T... Carusi, C.P. (2005). Exposure to movies smoking: its relation to smoking imitation among US adolescents. Pediatrics, 116(5): 1183-1191.

Udofia, N. \& Tom, E.O. (2013). Evaluation of Nollywood movies' explicit contents and the sexual behaviour of youths in Nigerian Secondary schools. Research on Humanities and Social Sciences, 3(5): 77-84.

Ugoji, F. N. (2014). Determinants of risky sexual behaviours among secondary school students in Delta State Nigeria. International Journal of Adolescence and Youth, 19(3), 408-418. https://doi.org/10.1080/02673843.2012.751040 